NWI-ID-2005-115

Revision 0

\title{
Coupling of Realistic Rate Estimates with Genomics for Assessing Contaminant Attenuation and Long-Term Plume Containment - \\ Task 4: Modeling \\ Final Report
}

Award DE-FG07-02ER63510

October 2005

Principal Investigator: Robert C. Starr

Awardee:

North Wind, Inc.

Collaborators:

Idaho National Laboratory

University of Idaho 


\section{Executive Summary}

Trichloroethene (TCE) is one of the most common groundwater contaminants. Under certain conditions, TCE can be degraded by microorganisms that occur naturally in the subsurface. Under anaerobic conditions, TCE can be degraded in to less chlorinated compounds (dichloroethene and vinyl chloride) and ultimately into the non-chlorinated, non-hazardous end product, ethene, via a process known as anaerobic reductive dechlorination (ARD). Anaerobic reductive dechlorination is widely recognized as a TCE degradation mechanism in the groundwater remediation community, and is used in active groundwater remediation systems and in monitored natural attenuation (MNA). Monitored natural attenuation relies on natural processes, such as dispersion and degradation, to reduce contaminant concentrations to acceptable levels without active human intervention, other than monitoring. TCE can also be biologically degraded under aerobic conditions via cometabolism, in which microbial enzymes produced for other purposes (such as oxidizing simple hydrocarbons to obtain energy) fortuitously also react with TCE. In cometabolism, TCE is oxidized directly to non-hazardous products. Cometabolism as a TCE degrading process under aerobic conditions is less well known than ARD. Natural attenuation is commonly discounted as a viable remedial alternative for TCE due to the presence of aerobic conditions, based on the paradigm that TCE is biodegradable under anaerobic conditions but not aerobic conditions. Contrary to this paradigm, TCE was shown to degrade relative to conservative co-contaminants at an environmentally significant rate in a large (approximately $3 \mathrm{~km}$ ), long TCE plume in aerobic groundwater at the Idaho National Laboratory (INL). Monitored natural attenuation was selected as the remedy for most of this plume, resulting in a considerable cost savings relative to conventional remedial methods. Cometabolism was shown to be the degradation mechanism.

In an effort to determine if cometabolism might be a viable remedy at other sites with TCE contamination in aerobic groundwater, this study examined TCE plumes at Department of Energy (DOE) facilities to evaluate whether TCE degradation in aerobic groundwater commonly occurs, and if degradation rates are fast enough that natural attenuation could be a viable remedy for TCE-contamination in aerobic groundwater. One hundred and twenty seven plumes at 24 DOE facilities were screened, and 14 plumes were selected for detailed examination. Plumes were selected for further study in part because a conservative co-contaminant was present. Spatial changes in the concentration of the co-contaminant were used to compensate for the effects of mixing and changes over time in the release of TCE from the contaminant source. Declines in TCE concentration along a flow path in excess of the decline in concentration of co-contaminant were attributed to degradation, which was assumed to be cometabolism. This study indicated that TCE was degraded in 9 of the 14 plumes examined, with first order degradation half-lives ranging from approximately 1 year to approximately 12 years. The observation that TCE appears to be degraded in about two-thirds of the plumes examined suggests that cometabolism of TCE in aerobic groundwater is a common occurrence in contrast to the conventional wisdom that TCE is recalcitrant in aerobic groundwater. The degradation half-life values calculated in this study are short enough that natural attenuation may be a viable remedy in many aerobic plumes. 
Computer modeling of groundwater flow, contaminant transport, and contaminant degradation is frequently used to predict the evolution of groundwater plumes, and is often used in evaluating natural attenuation and other remedies for contaminated groundwater. An important aspect of a computer model is the mathematical approach for describing degradation kinetics. One of the most common approaches is to assume that degradation is a first-order process (i.e., the rate of degradation is proportional to the concentration of the contaminant). First order kinetics are straightforward to incorporate into flow and transport models and require only a single value (a degradation half-life) to describe reaction kinetics. The use of first order kinetics is often justified in many cases because more elaborate kinetic equations closely approximate first order kinetics under typical field conditions. A previous modeling study successfully simulated the INL TCE plume using first order degradation kinetics.

TCE cometabolism is the result of TCE reacting with microbial enzymes that were produced for other purposes, such as the oxidation of methane to obtain energy for other microbial processes. Both TCE and the compound for which the enzyme was produced (the growth substrate) compete for enzyme reactive sites, and the presence of one interferes with reactions with the enzyme by the other. This is known as competitive inhibition. It was assumed that a competitive inhibition kinetic expression would be more technically rigorous than a first order decay kinetic model. Two activities were undertaken to evaluate this assumption. First, a research collaborator conducted a laboratory study to measure the parameters of this kinetic model under conditions similar to those of the INL TCE plume. The results of this lab study will be used in a flow and transport model for TCE in groundwater. This study will compare transport simulated using these measured values with transport simulated using kinetic parameter values reported in the literature, although literature values are typically for actively growing microorganisms, in contrast to the steady-state, near starvation conditions in the INL TCE plume. Second, modification of flow and reactive transport simulation software (Reactive Transport in Three Dimensions - RT3D) to include a competitive inhibition kinetic model was begun. After completing this development, the modified flow and transport model can be used to evaluate the sensitivity of simulated plume evolution to the choice of either a first order or competitive inhibition model, and to compare simulated results using lab measured and literature kinetic parameter values. 


\section{CONTENTS}

1. GOALS, OBJECTIVES, AND ACCOMPLISHMENTS ................................................1

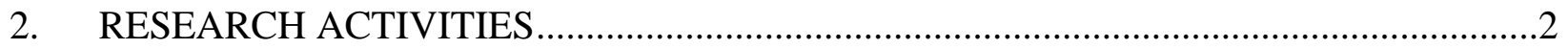

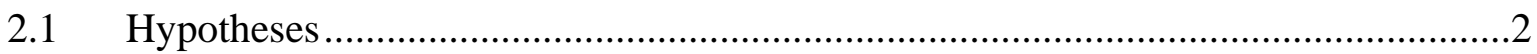

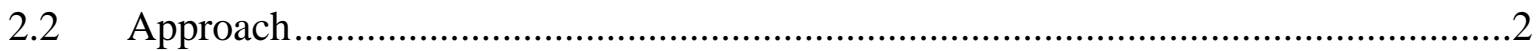

2.3 Problems, Departures from Plans, and Effects on Project Results .........................4

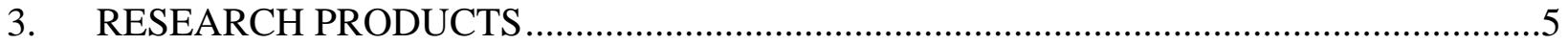

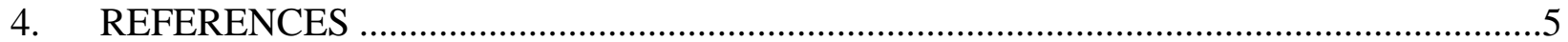




\section{GOALS, OBJECTIVES, AND ACCOMPLISHMENTS}

The goals and objectives of this research, and the associated accomplishments, are tabulated below.

\begin{tabular}{|c|c|}
\hline Goal / Objective & Accomplishment \\
\hline $\begin{array}{l}\text { Develop a conceptual model of } \\
\text { aerobic TCE cometabolism }\end{array}$ & $\begin{array}{l}\text { - Based on companion studies by project } \\
\text { collaborators, it was determined that TCE } \\
\text { cometabolism is performed under no growth, near } \\
\text { starvation conditions by the indigenous microbial } \\
\text { community } \\
\text { - A competitive inhibition enzyme kinetic model was } \\
\text { selected for use in a simulation study }\end{array}$ \\
\hline Develop a mathematical model & $\begin{array}{l}\text { - An appropriate mathematical model was identified } \\
\text { from the literature }\end{array}$ \\
\hline $\begin{array}{l}\text { Incorporate this mathematical model } \\
\text { into a groundwater flow and transport } \\
\text { model }\end{array}$ & $\begin{array}{l}\text { - Software was identified that can simulate } \\
\text { groundwater flow, contaminant transport, and } \\
\text { kinetically controlled reaction, and that can have } \\
\text { user-defined kinetic models added } \\
\text { - A short course in modeling reactive transport was } \\
\text { completed using this software } \\
\text { - A generic TCE plume using a first order decay } \\
\text { kinetic model was simulated } \\
\text { - The approach for adding a user-defined kinetic } \\
\text { model to this software was identified, and } \\
\text { implementation was started on this kinetic model } \\
\text { - Worked with research collaborator to develop a lab } \\
\text { experiment for measuring degradation kinetics and } \\
\text { generating values needed to parameterize this model }\end{array}$ \\
\hline $\begin{array}{l}\text { Evaluate applicability to other DOE } \\
\text { sites }\end{array}$ & $\begin{array}{l}\text { - It was determined that TCE degradation in aerobic } \\
\text { plumes occurred in } 9 \text { of } 14 \text { plumes examined at } \\
\text { DOE sites, and was concluded that biodegradation } \\
\text { of TCE in aerobic groundwater may be a common } \\
\text { occurrence } \\
\text { - Degradation half-life values of } \sim 1 \text { to } 12 \text { years were } \\
\text { determined in these plumes, and it was concluded } \\
\text { that degradation is fast enough that natural } \\
\text { attenuation is worthy of consideration for TCE in } \\
\text { aerobic groundwater }\end{array}$ \\
\hline
\end{tabular}




\section{RESEARCH ACTIVITIES}

\subsection{Hypotheses}

The following hypotheses are specific to this task:

1. Preferential attenuation of TCE in aerobic groundwater, presumably as a result of cometabolism, is a common occurrence,

2. The TCE degradation rate may be fast enough that MNA could be a viable remedy in some situations, and

3. TCE transport simulated using a model that describes cometabolism kinetics may differ from transport simulated using first-order decay kinetics.

\subsection{Approach}

The following approach was implemented:

The degradation rate and frequency at which TCE attenuation in aerobic groundwater occurs were evaluated by examining TCE plumes in aerobic groundwater across the DOE complex. One hundred and twenty seven plumes at 24 DOE facilities were screened to identify plumes with the characteristics needed to apply the tracer corrected method for determining the degradation half-life, and 14 plumes were identified for detailed study. The screening characteristics included aerobic conditions, plume length of 1,000 ft or more, several monitoring wells along a flow path, and the presence of both TCE and a conservative co-contaminant. The conservative co-contaminant is a constituent that is thought to be derived from the same contaminant source as TCE, and has transport characteristics similar to those of TCE, but is not degraded under aerobic conditions. In this study, tetrachloroethene, carbon tetrachloride, and technetium-99 were used as co-contaminants. It is assumed that variations in mass transfer from the contaminant source and transport process (other than degradation) affect TCE and the conservative co-contaminant similarly, and therefore TCE degradation is expressed as enhanced attenuation along a groundwater flow path relative to the conservative co-contaminant. If the groundwater flow velocity is known and degradation is assumed to be a first order process, then the degradation half-life can be determined from a plot of the ratio of the concentration of TCE to conservative co-contaminant versus distance along a flowpath. Details of this study were presented in the Year 1 Progress Report for this project (Starr et al., 2004), and the tracer corrected method is described in Sorenson et al. (2000).

Application of the tracer corrected method to data from TCE plumes in aerobic groundwater at DOE facilities indicated that TCE is preferentially attenuated relative to a conservative co-contaminant in 9 of the 14 plumes examined. TCE degradation half-life values calculated for these plumes range from slightly less than 1 year to 12 years, with TCE degradation in several plumes having a half-life of approximately 4 years. These results led to the conclusion that TCE degradation in aerobic groundwater is probably a common occurrence. Although many site-specific factors influence whether a given degradation half-life is short enough that MNA would be a feasible remedy, or at least a component of a suite of remedies at different times or places in a plume, our assessment of the relatively short half-life values 
calculated for the plumes examined is that MNA may indeed be a feasible remedy in many situations. As a point of reference, the TCE degradation half-life for the TCE plume at the INL was longer than the values calculated in this study, and MNA was selected as a remedy for most of that plume. Therefore, our conclusion is that MNA should be considered as a remedy in aerobic groundwater. This is in contrast to common practice in which the existence of aerobic conditions is sufficient grounds for excluding MNA from further consideration.

Following the evaluation of TCE degradation in aerobic groundwater, activities focused on modeling TCE transport in groundwater with cometabolism as the degradation mechanism. Research conducted in other tasks of this project and in other projects indicated that cometabolism was the mechanism responsible for TCE degradation in the INL TCE plume and in other TCE plumes in aerobic groundwater; therefore, the kinetics of cometabolism were further investigated. Cometabolism is a process in which enzymes produced to react with a target compound in order to produce some beneficial result for the microorganism that produced the enzyme fortuitously also react with a non-target compound, with no benefit to the organism. For example, enzymes produced to react with methane or other simple hydrocarbons to produce energy for microbial processes also react with TCE. This process reduces TCE concentrations but does not yield energy to the microorganism. This process may even be detrimental to the enzyme-producing microorganism in that reaction of TCE with the hydrocarbon oxidizing enzyme interferes with hydrocarbon oxidation, and hence reduces the amount of energy available to the microorganism. The interaction between a target substrate and a non-target substrate is known as competitive inhibition. It was decided to describe TCE cometabolism using a competitive inhibition kinetic model. A mathematical description of competitive inhibition described in "Kinetics of Aerobic Cometabolism of Chlorinated Solvents" (Alvarez-Cohen and Speitel, Jr., 2001) was adopted for further work in this project.

The next step was to develop a groundwater flow and transport model that included reactive transport. Modeling software that has the most of the necessary functionality was identified. This software is the Groundwater Modeling System (GMS; Environmental Modeling Systems, Inc., South Jordan, Utah), which is a graphical user interface for the groundwater flow simulator MODFLOW, and the reactive transport simulator Reactive Transport in Three Dimensions (RT3D; Clement, 1997; Clement et al., 1998), both of which are widely used software packages, and other related software packages. Although RT3D includes several kinetic expressions, it does not include a competitive inhibition expression. However, RT3D allows user-defined kinetic expressions to be added. A reactive transport modeling short course was attended to become familiar with using GMS to perform simulations in this study. TCE transport with first-order decay was successfully simulated for a hypothetical plume using GMS. Although development of a user-defined kinetic expression is touted as a feature of RT3D, implementing the competitive inhibition equations as a kinetic model in RT3D was more difficult than anticipated, and this activity was still in progress at the conclusion of the second project year. After completing this code development, the enhanced RT3D software can be used to investigate the sensitivity of TCE transport simulations to the selection of either a first-order decay model or a competitive inhibition model. First-order decay is a commonly used kinetic model for simulating contaminant transport. In part, its popularity results from the need for only a single term to fully parameterize the kinetic model, while more rigorous, albeit more complex, kinetic models require more parameter values. For example, a competitive inhibition model requires four parameter values. For field cases, it is often extremely difficult to obtain these 
parameter values, and hence a more elegant, technically rigorous kinetic model often cannot be justified. The future sensitivity study is intended to elucidate the effect of using a first-order model compared to a more complex kinetic model.

The competitive inhibition model can be parameterized using either value published in the literature or from lab studies performed during this project. We elected to use parameter values measured in the lab under conditions that are representative of conditions in the INL TCE plume, namely a stable microbial community existing under near starvation conditions, that utilize methane as a carbon source and cometabolize TCE using methane monooxygenase enzymes. Cometabolism rate parameters were measured under methane concentrations typical of the INL TCE plume, and at a range of TCE concentrations similar to those in the distal portion of the plume. Upon completion of the model development task, the sensitivity of TCE transport simulations to lab-derived, representative kinetic parameters compared to literature derived parameter values can be evaluated. Literature values were typically derived from conditions that differ from the no-growth, starvation conditions in the INL TCE plume and that are suspected to be common elsewhere.

The tracer-corrected method in this study was used to investigate the frequency and rate of TCE degradation in aerobic groundwater, and it was concluded that TCE commonly degrades at an environmentally significant rate in most of the plumes examined. It is reasonable to expect that the same approach could be used to assess TCE degradation in other plumes and to evaluate MNA as a remedy for TCE plumes in aerobic groundwater. However, the widespread applicability of the tracer corrected method is limited by the requirement that a conservative co-contaminant with a similar source function and transport properties be commingled with TCE. This requirement is not met in many aerobic TCE plumes and in others, the co-contaminant itself is a hazardous constituent that would require remediation even in the absence of TCE. Enzyme activity probes (Keener et al., 1998) developed elsewhere are promising alternatives to the tracer corrected method for assaying TCE degradation. Enzyme activity probes have historically been used to demonstrate that the enzymes involved in TCE co-metabolism are both present and active in a groundwater microbial community (e.g., Lee et al., 2005), thereby providing convincing evidence that TCE co-metabolism is occurring. Extension of this technique for determining field degradation rates, as opposed to a simple present/absent assessment, is underway by third parties. This development will provide a method for both demonstrating that TCE degradation via cometabolism is occurring and for determining a defensible degradation rate. The enzyme activity probe technique is not limited by the requirement that a conservative co-contaminant coexist with TCE, and therefore it should be more broadly applicable than the tracer corrected method and will facilitate assessing the feasibility of MNA as a remedy for TCE in aerobic groundwater.

\subsection{Problems, Departures from Plans, and Effects on Project Results}

The only significant departure from the planned research is that developing the enhanced kinetic expression for RT3D was not completed as a result of this activity being more time consuming than anticipated. Therefore, comparing TCE transport simulated with various kinetic models has yet to be accomplished. 


\section{RESEARCH PRODUCTS}

- A report that provides complete documentation of evaluation of aerobic TCE degradation at selected DOE plumes:

o Starr, R.C., M.C. Koelsch, and K.S. Sorenson, Jr., 2004. EMSP Annual Report: Coupling of Realistic Rate Estimates with Genomics for Assessing Contaminant Attenuation and Long-Term Plume Containment - Task 4: Modeling. NW-ID-2004-062.

- Two conference presentations:

o Koelsch, M.C., R.C. Starr, and K.S. Sorenson, Jr., 2005. “Assessing aerobic natural attenuation of trichloroethene at four DOE sites," $31^{\text {sr }}$ Waste Management Symposium, WM Symposia, Inc., Tucson, Arizona, February 27 - March 3.

o Starr, R.C., M.C. Koelsch, L.N. Peterson, and K.S. Sorenson, Fr., 2005. “Assessing aerobic attenuation of trichloroethene using the tracer-corrected method," Eighth International In Situ and On-Site Bioremediation symposium. Battelle, Baltimore, Maryland, June 6-9.

- One journal article (in review):

o Starr, R.C., M.C. Koelsch, M. Hope Lee, and K.S. Sorenson, Jr., 2005. “An evaluation of the frequency and rate of natural attenuation of trichloroethene in aerobic groundwater at 14 sites,” Bioremediation Journal.

\section{REFERENCES}

Alvarez-Cohen, L, and G.E. Speitel, Jr., 2001. "Kinetics of aerobic cometabolism of chlorinated solvents,” Biodegradation 12: 105-126.

Clement, T.P., 1997. RT3D - A Modular Computer Code for Simulating Reactive Multi-Species Transport in 3-Dimensional Groundwater Aquifers. Pacific Northwest National Laboratory, Richland, WA. PNNL-11720.

Clement, T.P., Y. Sun, B.S. Hooker, and J.N. Peterson, 1998. "Modeling multi-species reactive transport in groundwater aquifers,” Groundwater Monitoring \& Remediation 18: 79-92.

Keener, W.K., M.E. Watwood, and W.A. Apel, 1998. “Activity-dependent fluorescent labeling of bacteria that degrade toluene 2,3-dioxygenase," Applied Microbiology and Biotechnology 49: 455-462.

Lee, M.H., O.P. Leiser, S.S. Collins, K.A. Hall, J. Witt, D.L. Dettmers, R.A. Wymore, and M.F. Skelly, 2005. "Characterization of aerobic TCE degradation potential in two contaminated groundwater sites at Sandia national Laboratories, New Mexico,” Proceedings of the Joint International Symposia for Subsurface Microbiology and Environmental Biogeochemistry, August 14-19, Jackson Hole, Wyoming.

Sorenson, K.S., Jr., L.N. Peterson, R.E. Hinchee, and R.L. Ely, 2000. “An evaluation of aerobic trichloroethene attenuation using first-order rate estimation,” Bioremediation Journal 4:337-357.

Starr, R.C., M.C. Koelsch, and K.S. Sorenson, Jr., 2004. EMSP Annual Report: Coupling of Realistic Rate Estimates with Genomics for Assessing Contaminant Attenuation and Long-Term Plume Containment - Task 4: Modeling. NW-ID-2004-062. 